\title{
PEDAGOGIAS DOS CORPOS EXCITÁVEIS E MODULÁVEIS: SEXO, AMOR E INSATISFAÇÕES AOS VINTE CINCO ANOS DA REVISTA NOVA COSMOPOLITAN
}

Dolores Galindo ${ }^{1}$

Resumo: Este artigo discute a abordagem das temáticas amorosa e sexual na revista feminina Nova Cosmopolitan. Foram analisados vinte e quatro exemplares publicados entre 1997 e 1998, período que coincide com a comemoração dos 25 anos do periódico no Brasil. Na revista em questão, o sexo se inscreve na busca pela intensificação das sensações, avizinhando-se do consumo de exercícios que faz da academia de ginástica um dos espaços centrais na contemporaneidade. A exacerbação das sensações substitui o controle e ocultação dos corpos que, historicamente, caracterizou a apresentação do sexo na imprensa feminina, sendo, ambos, incorporados à lógica do consumo mantida pela insatisfação e busca de sensações exacerbadas pedagogias de corpos excitáveis do orgasmo e moduláveis da ginástica.

Palavras-chave: pedagogias da sexualidade, amor, sexo, imprensa feminina. 


\section{Introdução}

A revista feminina Nova Cosmopolitan é marcada pelo enaltecimento do sexo que ocupa lugar de destaque em suas capas e matérias. O sexo é o grande ponto de venda da Nova. Nascida da literatura, a imprensa dirigida ao público feminino, desde o início, trouxe para as suas páginas a temática amorosa que se mantém até hoje como fonte de novidade. A temática sexual, por sua vez, possui ingresso mais recente nesse tipo de publicação. $\mathrm{O}$ amor sempre foi considerado um assunto feminino, o sexo se tornou constante apenas na segunda metade do século XX.

A literatura sobre revistas femininas aponta que estas, ao longo do século XIX, configuraram-se como dispositivos pedagógicos que atuam na constituição de corpos e sexualidades, tradição esta fortalecida no Brasil desde o século XIX (BULTONI, 1981; GALINDO, 1999), prolongada, também, nos séculos seguintes (LOURO, 2001; XAVIER, 2007, ZUCCO e MINAYO, 2008). No ideário romântico, a sexualidade ocupa status inferior ao amor. É socializada de modo a acreditar ser possível sentir atração sexual por uma pessoa que mal se conhece. $\mathrm{O}$ amor, por sua vez, é um evento raro, dirigido a pessoas especiais e com menor frequiência que a atração sexual. (COSTA, 1997).

Tal modelo de amor, ao longo da história, foi aderido ao feminino, de modo que 'por natureza' a mulher uniria sexo e amor, pensaria numa parceria eterna, além de ser mais passível de se envolver afetivamente. $\mathrm{O}$ amor passou a constituir a outra face do feminino. Em tal ideário, sexo e amor, particularmente para as mulheres, foram unidos sob o rótulo de uma paixão terna. Para a mulher só se poderia falar em plena satisfação sexual quando vinculada ao sentimento amoroso: distante deste tem-se sofrimento e culpa.

Esse artigo discute como o sexo e o amor são abordados na revista feminina Nova Cosmopolitan como um dos caminhos para a compreensão das pedagogias da sexualidade e seus deslocamentos em relação ao ideário romântico. Foram analisados vinte e quatro exemplares publicados entre 1997 e 1998, período que coincide com a comemoração dos 25 anos do periódico no Brasil, sendo focalizadas todas as capas e as matérias que tinham nos temas sexo e amor seus elementos centrais. 
Na primeira sessão, realizamos um breve histórico sobre o destaque crescente conferido ao sexo na imprensa feminina. Na segunda sessão, por sua vez, fazemos uma breve exposição sobre a revista Nova Cosmopolitan, oferecendo alguns dados sobe sua fundação, objetivos e forma de diálogo com o leitor. Na terceira e na quarta sessão, abordamos os sentidos sobre sexo e amor, considerando os editoriais, matérias e capas dos exemplares publicados entre 1997 e 1998, em relação aos quais foi feita análise temática (BARDIN, 1977). Na última sessão, passamos às considerações finais que dizem respeito ao lugar do corpo no contexto da relação entre os sentidos do amor e do sexo que circulam na revista.

\section{Nas páginas da imprensa feminina brasileira: do amor ao sexo}

Nas páginas dos jornais da primeira década do século XX, opúsculos foram escritos de modo a demonstrar como o casamento está relacionado à saúde: a virgindade prolongada geraria diversos males físicos e morais. Dever-se-ia também evitar o casamento infecundo, no qual a sexualidade seria exercida sem fins reprodutivos. Tal vivência sexual é lida como indicativa de desordem, uma vez que o verdadeiro objetivo deveria ser o empenho no estabelecimento de um amor conjugal sereno e saudável (MALUF e MOTT, 1998). Questionava-se a possível inclusão do sexo na educação feminina. Era adequado informar as moças sobre seu aparelho reprodutor? Até que ponto essas informações poderiam servir de estímulos para possíveis experiências sexuais?

No início do século, apoiados em princípios científicos, ideólogos e educadores discutiam sobre a propriedade ou não de serem ministradas noções sobre sexo aos jovens, principalmente às moças. Divulgar manuais de educação sexual para a juventude seria um estímulo para concupiscência? Foi aberto espaço para as discussões acerca do sexo de cunho científico e moral, dimensões bastante interligadas nesse contexto. Tal discussão culminará com tímidos artigos sobre sexo a ser publicados na década de 40.

Na década de 50, a imprensa já reflete a maior participação da mulher na esfera pública, porém, na imprensa feminina permanece a 
rígida moral tecida nos anos anteriores e a imagem é basicamente a da dona de casa. $\mathrm{O}$ discurso centra-se, sobretudo, no amor conjugal e no aperfeiçoamento das habilidades domésticas. Afirma-se constantemente que a adequação e legitimidade da parceria amorosa não estariam na atração entre os parceiros, mas na futura família a ser criada. O sexo ainda era tratado de forma bastante indireta, camuflado em meio ao discurso amoroso.

Na primeira metade dos anos 60, o sexo ganha maior espaço nas revistas femininas, que refletem uma erotização do casamento e passam a admitir o desempenho sexual como elemento fundamental para o êxito do relacionamento. É característica dessa época uma crise simbólica: questionam-se conjuntos de valores, normas e sentimentos tradicionais, introduzem-se novos códigos de conduta. Prolifera-se a idéia de que o casamento enquanto instituição está em crise - ser a boa dona de casa da década de 50 não mais garante o futuro do matrimônio.

Os aspectos mais debatidos na década de 60 estavam relacionados à relação homem-mulher e, particularmente, ao funcionamento do casamento. Nesse período, questiona-se: (1) virgindade e pureza femininas como pré-requisito para o casamento; (2) segregação dos papéis conjugais baseados numa moral assimétrica; (3) religião passa a ser associada a uma moral repressiva e obsoleta e, por fim, (5) a reprodução biológica imediata após o casamento vista como algo que diminui a liberdade dos cônjuges (NICOLACI-DA-COSTA, 1985).

A imprensa feminina, imersa neste contexto social, passa a se preocupar em fornecer estratégias às leitoras diante da crise no casamento. Para as mulheres educadas como "moças de família", o exercício da sexualidade desvinculada do objetivo reprodutivo constituía concupiscência, deparam-se com a necessidade de se colocarem como objeto de desejo sexual para o marido. O sexo emerge apoiado com um aval científico, o mesmo que outrora o definira como assunto impróprio para mulheres. Um bom desempenho sexual passa a ser um dos itens responsáveis pelo sucesso ou insucesso do casamento, criase um espaço social para se falar de sexo.

Simultaneamente à preocupação com a "salvação" do casamento, passa a insinuar-se outro discurso: o do prazer feminino. Nesse contexto, o sexo, não mais o 'purificado' ou ligado a fins 
reprodutivos, mas associado ao prazer, é introduzido ao léxico feminino e nas páginas das revistas. Constrói-se a imagem de uma nova mulher marcada pela sedução, mulher que se apresenta diante do outro como objeto sexual por decisão individual. Carmem da Silva, jornalista da revista Cláudia, em 1963, compara a dona de casa a uma rainha triste o que atribui à conservação de antigos preconceitos centrados, sobretudo, na idéia de que a mãe de família deve policiar sua vida sexual, não se permitindo "certas coisas".

Na década de 70, o movimento de ampliação da discussão sobre sexo na imprensa culmina na publicação de artigos centrados exclusivamente na questão sexual, chegando a conter descrições detalhadas dos órgãos sexuais. É nesse contexto de intensas transformações que em 1973 a revista Nova é lançada pela editora Abril. Essa revista se diferencia das demais congêneres por uma abordagem mais direta da questão sexual e pela adoção da revisão dos papéis sexuais masculinos e femininos como carro-chefe.

O surgimento de uma revista, como a Nova, que tem como proposta falar francamente sobre sexo tornou-se possível pelas transformações discutidas anteriormente, mas também pela diminuição da censura interna das editoras e da censura restritiva. Até o final da década de 60, encontrávamos algumas matérias abordando o assunto sexo de maneira mais informal como na revista Cláudia. Com o fim da ditadura, houve uma explosão do sexo na imprensa, o que coincide com o lançamento da revista Nova (1973), que pela primeira vez inclui o sexo como um dos itens axiais na proposta editorial de revistas femininas no Brasil.

\section{A revista Nova Cosmopolitan publicada no Brasil}

A revista Nova, publicada pela editora Abril, foi criada visando prioritariamente atingir a mulher de camada média que pode consumir os diversos produtos que são anunciados em suas páginas. É uma revista de comportamento cujo conteúdo não é composto de fatos, mas de novidades que podem ser reedições de conteúdos milenares, desde que relidos sob o prisma de uma preocupação moderna - o 
aumento do prazer sexual. Os temas são abordados como atemporais - marca da imprensa feminina desde a sua origem.

Um segundo traço que chama atenção é o forte apelo ao consumo. As suas páginas estão cheias de anúncios e em muitas delas explicitados preço e local onde podem ser encontrados os produtos. Mas, na Nova, não é diretamente a roupa ou a maquiagem anunciadas que interessam, mas a possibilidade de seduzir, de encantar ou de ser feliz. As roupas ou outros produtos são contextualizados no âmbito de uma cena em que há uma mulher sedutora ou um casal que lança entre si olhares insinuantes.

De acordo com Moraes (1981), a mulher da revista Nova é agressiva e conflita com padrões sociais vigentes em busca de alternativas mais satisfatórias. Agressiva, mas que não quer deixar de ser feminina. Em consonância com esse modelo, os assuntos centrais são: o sexo, o amor e a beleza. Em menor escala, encontram-se também matérias sobre mercado de trabalho e atualidades. Assuntos de cunho doméstico são pouco mencionados e quando o são, sempre estão relacionados a aspectos relativos à 'vida a dois'. É em torno da relação homem-mulher que giram as temáticas abordadas pela revista.

Apesar de ser publicada no Brasil, a Nova é vinculada a uma rede internacional de revistas - a Cosmopolitan - sediada em Nova York, sob a responsabilidade da Corporação Hearst, que abrange países de culturas diversas, como por exemplo, Índia, França e Estados Unidos. Ante tal diversidade, procura-se manter uma unidade entre as diversas edições nacionais, de modo que mesmo as matérias locais conservem o estilo Cosmopolitan associado às idéias de modernidade e emancipação feminina. Para isso, não necessariamente, a maioria das matérias foi escrita por americanos. Até 1984, a participação de matérias assinadas por autores norte-americanos na Nova era de, aproximadamente, 15\% (MORAES, 1981).

Deve-se ressaltar que, mesmo pertencendo à rede de revistas mencionada, a Nova não é uma simples transcrição da similar americana. As matérias publicadas na Nova, ainda quando assinadas por um autor americano, são selecionadas tendo como parâmetro o universo cultural brasileiro, de modo a torná-las condizentes com o conjunto de valores das leitoras. Caso contrário, a revista não 
sobreviveria. A relação entre emissor e receptor é um relação de troca, na qual há sempre uma moeda, que no caso da imprensa escrita é o índice de vendas, que se reflete na tiragem da revista. Se de um lado os meios de comunicação difundem sentidos circulantes no imaginário social em determinado momento, de outro, também produzem sentidos singulares em relação ao imaginário social que tomam como fonte de ancoragem. Assim, a revista se configura como um espaço de difusão de sentidos circulantes e de produção de novas significações.

Ao longo das matérias, editoriais e cartas de leitoras, constróise para a Nova uma personalidade, uma identidade. A Nova é ousada, é liberada. Nova "acha", Nova "pensa" e ao mesmo tempo no conjunto de matérias, a Nova não se posiciona. Há uma personificação que abarca sentimentos, sentidos e comportamentos. Assim, em editorial publicado em agosto de 1998, escreve-se acerca de especial sobre sexo "lacrado para adultos", escreve-se:

A Nova sempre foi ousada ao tratar as questões sexuais. Nestes 25 anos, tentamos sempre estar a frente desses discursos, dando todo o tipo de esclarecimento as nossas leitoras. Muitas vezes, geramos polêmica com nossa franqueza. Não temos medo. Sabemos que você, leitora, espera isso de nós. (07/98).

O jeito de ser da Nova é semelhante ao modelo de mulher apregoado pela revista: liberada, ousada e, sobretudo, aberta para novas aprendizagens sobre sexo. Desde seu primeiro editorial, a revista coloca a "abordagem franca" das questões relacionadas ao sexo como um diferencial em relação aos demais periódicos dirigidos ao público feminino. Em edição comemorativa de 25 anos da revista, tal proposta foi trazida como um trunfo, uma conquista não apenas da revista, mas das mulheres como categoria social. Nos anos noventa, o caráter transgressor do falar sobre sexo é minimizado, uma vez que na sociedade atual este virou assunto quase obrigatório nos discursos dos leigos e especialistas. Falar de sexo por si só não é mais considerado um ato transgressor. 


\section{Lançando o olhar sobre as capas: o sexo enaltecido}

A cada edição, cerca de cinqüenta por cento ou mais das chamadas de capa ${ }^{2}$ são dedicadas às temáticas amorosa e sexual. Pretendendo compreender o lugar destinado às temáticas sexual e/ou amorosa nas capas, tentou-se por realizar um levantamento de quantas chamadas de capa tratavam das temáticas sexual e/ou amorosa isoladamente em cada número. Acreditava-se poder identificar com clareza as chamadas de capa que faziam menção a outra temática, entretanto, isso se tornou inviável, porque parte das chamadas de capa eram bastante ambíguas, não podendo ser identificadas.

Algumas chamadas eram bem claras quanto ao seu vínculo com a temática sexual, a exemplo da publicada em julho de 1997: "O que os Homens acham das mulheres que se masturbam". Outras explicitavam com nitidez a sua estreita relação com a temática amorosa como a publicada no número março de 1998: "Como fazer um homem se apaixonar por você”. Algumas delas, entretanto, conduziam a uma série de dúvidas: "Por que os homens somem na manhã seguinte e o que faz eles ficarem?" (02/98). Se por um lado, nessa chamada abordase o sexo, o interesse que está na base dessa chamada é identificar se 'ele' pretende ou não estabelecer um vínculo afetivo.

As capas representam, em geral, o primeiro contato entre o veículo de comunicação e o leitor. Nas bancas, durante o ato da leitura, podem ou não despertar interesse, conduzindo a continuar a leitura ou a compra. Se para a leitora esses podem ser rápidos instantes e sobre o quais refletem muito pouco, para a revista esse é um momento crucial. Todo um esforço técnico é dirigido para que a capa se constitua um convite à compra pelo público a que se destina. Por trás das chamadas expostas nas capas, há o contexto de produção que regula, mantém e legitima uma identidade à revista regida pela lógica do mercado: a revista deve vender.

As informações e recursos gráficos utilizados nas capas pressupõem um processo de seleção acurado, de modo que a ênfase na questão sexual não é aleatória. Tomando uma metáfora extraída dos jogos de baralho, nelas estão os trunfos lançados para que o produto seja de interesse do leitor/ consumidor: o sexo parece ser uma de suas 
principais cartas. Mesmo nas chamadas mais diretamente relacionadas à temática amorosa, com frequência destacam-se aspectos ligados ao sexo. O restante das chamadas é distribuído entre assuntos relativos à saúde, beleza e moda, sempre vinculados, de um modo ou de outro, ao relacionamento homem-mulher que constitui o eixo central da revista.

A tônica sexual também está presente na personagem da capa. A mulher é fotografada usando transparências ou roupas que evidenciem o corpo, a sensualidade. $\mathrm{O}$ olhar expressa agressividade, uma postura insinuante. Essa imagem é quase homogênea ao longo dos números, reforçando a proposta da revista explicitada desde o seu editorial inicial, a de ter como público-alvo a mulher, liberada sexualmente e moderna, que procura novos valores.

Tais personagens condensam as características femininas valorizadas pela revista. Vala e Ordaz (1998), ao estudarem a representação social do suicídio na imprensa escrita, apontam para a 'personificação' como modalidade de objetivação. Personificar significa associar uma pessoa a um conceito ou fenômeno, dando forma e realidade empírica às abstrações. Também significa incorporar a essa idéia espaços de sentido decorrentes da história de vida da personagem. As mulheres da capa - figuras centrais na disposição gráfica destas personificam a liberação sexual, felicidade e emancipação propostas pela Nova, tríade que, de acordo com Moraes (1986), compõe o tripé de sustentação da revista.

O caráter utilitário, presente na Nova desde sua fundação, parece ser o carro-chefe da linha editorial. Nesse sentido, as capas procuram evidenciar a qualidade e raridade das informações disponibilizadas. Em setembro de 1997, por exemplo, "presenteia-se" a leitora com um "Guia Secreto da Leitora Nova" que, nas palavras da revista, responderia às perguntas que não seriam feitas à melhor amiga. Seguindo o enfoque instrumental, as chamadas relativas ao sexo e ao amor se centram na oferta de guias de conduta. Constrói-se o efeito de sentido de que tanto no sexo como no amor, pode-se obter a satisfação almejada, para isso basta conhecer o que as páginas anunciadas nas capas têm a dizer.

As capas devem materializar não só o que o leitor vai encontrar 
nas páginas seguintes, mas a proposta do periódico como um todo. As chamadas mais diretamente relacionadas à questão sexual giram em torno da oferta de técnicas para aprimoramento do desempenho sexual, que podem incluir: maior conhecimento sobre o corpo, preferências masculinas e femininas, bem como informações sobre técnicas de aumento do prazer, com destaque para as denominadas posições sexuais e fantasias eróticas. Essa preocupação com o sexo é objetivada através da alusão ao orgasmo. Veja-se: (1) "O Segredo Sexual dos Cinco Segundos. Uma pista: inclui o ponto G dos Homens" (11/98); (2) "Como dar ao seu amado o melhor orgasmo da vida dele. (Com o tipo de sexo que os homens gostam" (03/97); (3) "12 pequenas mudanças para você fazer mais sexo ... e muito melhor" (06/97).

As chamadas mais relacionadas à temática amorosa, por sua vez, possuem duas preocupações básicas. A primeira preocupação seria a aquisição de conhecimentos sobre nuances do comportamento amoroso masculino. Saber como fazê-lo se apaixonar/se comprometer, bem como identificar as suas intenções. Veja-se: (1) "Como fazer qualquer homem se apaixonar por você?"“(03/98); (2) "Por que os homens somem na manhã seguinte e o que faz eles ficarem. É só seguir as pistas” (02/ 98); (3) "Quer casar comigo? A verdadeira razão que leva os homens a fazer (e a não fazer) essa pergunta" (12/97). A segunda preocupação seria oferecer estratégias para incremento da durabilidade de vínculos afetivos estabelecidos em parcerias monogâmicas e heterossexuais. Como ilustração, pode-se citar as seguintes chamadas: (1) "20 maneiras de manter seu amor à prova de traição." (05/98); (2) "Os casais nos anos noventa: o que une, o que desune, o que solidifica a relação" (09/ 98); (4) "As melhores coisas que você pode fazer pelo futuro do seu casamento" (07/98); (5) Mulheres contam como reacenderam o tesão em casamentos que andavam devagar, quase parando.

Nas chamadas da capas, geralmente, quando se fala de amor, salientam-se aspectos mais relacionados ao sexo. Quando se fala de sexo, por sua vez, este é frequentemente abordado de forma isolada da questão amorosa, estando centrado em técnicas ou informações relacionadas ao ato sexual em si. Desse modo, nas capas, a fala sobre sexo não remete necessariamente ao amor. Se a análise fosse interrompida nesse momento, afirmar-se-ia que o sexo é visto como 
mais importante do que o amor. Porém, as capas e as matérias mantêm entre si uma relação necessária em termos de significações produzidas, mas não de correspondência unívoca.

Lançando o olhar sobre as capas, depara-se com um enaltecimento do sexo, mas estudando as matérias às quais aludem, observa-se que a maioria delas se centra no contexto conjugal, tendo por pano de fundo uma preocupação amorosa. Aproximando-se da produção publicitária, as capas, em seu objetivo de persuadir o leitor, não necessariamente funcionam como espelhos fiéis das significações produzidas no corpo da revista. Constituem, antes de qualquer consideração mais específica, o resultado de um processo de seleção de conteúdos apresentados nas matérias, mas em função de critérios que têm o leitor como um dos seus principais crivos.

\section{Sexo: das sensações fugidias ao orgasmo como ápice}

Nas matérias analisadas, o sexo é significado como uma experiência que deve proporciona prazer: existe para satisfazer o indivíduo. Se a "vida sexual" não está boa, o problema está no sujeito. $\mathrm{Na}$ "cama", em princípio, tudo é permitido em prol do "prazer" individual, tudo é definido em função de uma "escolha". O que interessa é como o indivíduo se sente a respeito do que faz, por isso, nenhum sistema de normas exterior a isso deve ser levado em consideração. Na Nova, admite-se como premissa que o sujeito pode escolher as formas que quiser para viver sua sexualidade. O sexo assume estatuto semelhante a um bem de consumo - algo que pode ser adquirido e utilizado tendo como fim último a satisfação individual.

A revista reforça que a boa vida sexual depende exclusivamente do desejo/desempenho individual, expõe problemáticas que contradizem tal premissa. Na Nova, a sexualidade feminina ainda parece estar condicionada ao crivo de antigos valores que ganham voz, como: medos e inseguranças masculinas. Falar em um sistema de valores calcado em relações de gênero desiguais equivaleria a negar a emancipação feminina, vista como uma conquista das mulheres e que constitui um dos pilares da Nova.

Reconhecer o direito à vivência da sexualidade não significa 
que o sexo tenha deixado de ser um problema. Pode-se dizer que o problema foi deslocado. Um primeiro desdobramento pode ser situado na indagação sobre as dificuldades a respeito do exercício da referida liberdade diante das atitudes masculinas, que carregam mais do que um eco do passado. Um segundo desdobramento se caracteriza por uma das faces do "direito" ao prazer que é a obrigação de ter "prazer" o mais intenso e frequentemente possível - proposição, sem dúvida, aprisionante e que desperta conflitos.

Apesar de a satisfação ser vista como possível, através de qualquer meio escolhido por um sujeito livre e autônomo, descreve-se uma verdadeira hierarquia das experiências sexuais, ordenadas segundo a satisfação que pode ser proporcionada, hierarquia esta que tem como parâmetro a ligação sexo/amor.

Na busca pelo prazer, o desempenho sexual é visto como passível de ser aprimorado. O sexo emerge, então, como um conjunto de habilidades que podem ser treinadas/desenvolvidas. Aprendizagem e aperfeiçoamento estão condicionados aos conhecimentos e disposição à mudança. Assim, a maior parte das matérias procura oferecer novas tecnologias de aprimoramento do desempenho sexual, informações sobre os desejos masculinos, receitas para diminuir as inibições, bem como indicações para tratamento de problemas fisiológicos que estejam obstacularizando o prazer.

Duas metáforas utilizadas materializam com clareza a acepção do sexo como um conjunto de habilidades. A primeira assimila o sexo a uma modalidade esportiva. A segunda metáfora compara o sexo ao aprendizado para condução de um veículo, em matéria sobre experiências sexuais das quais os sujeitos se arrependem. Na edição de janeiro de 1997 afirma-se: “(...) Se você for fazer o teste prático para tirar carteira de motorista depois de ter tido apenas algumas aulas de auto-escola, vai se sentir insegura. (...) Não perderá tempo se recriminando: da próxima vez, é só treinar mais".

É o orgasmo, o sinalizador de que o prazer sensual foi obtido. Chegar ao orgasmo é o que se busca; através dele se explica e justifica o árduo percurso em busca de um prazer visto como acessível a todos. Descreve-se como se pode atingi-lo, as mudanças que podem ocorrer com o envelhecimento, a possibilidade de serem múltiplos, entre outros 
aspectos. Através do orgasmo, a busca mais genérica pelo "prazer" ganha um rótulo biologizante e objetivo, algo que pode ser descrito e identificado por sinais físicos, como intumescimento do clitóris, lubrificação, ritmo da respiração em meio a diversos outros.

Dirigem-se muitas atenções à descrição das técnicas para obtenção de um orgasmo mais longo, mais intenso. No especial "lacrado para adultos", publicado em julho de 1998, promete-se alongar um orgasmo em 179 vezes com um programa cientificamente apoiado que inclui etapas bastante delimitadas: masturbação, desenvolvimento dos músculos P.C. e uma última etapa, em conjunto com o parceiro, que demanda uma série de pré-condições: "Agora, ele precisa ficar numa posição confortável, na qual possa usar as duas mãos para estimular o clitóris e a vagina ao mesmo tempo. O resultado, segundo os pesquisadores, são ondas de orgasmos, numa intensidade que você nunca conheceu".

Para chegar ao orgasmo, é preciso esforço técnico e preparação psicológica, principalmente a revisão de valores adquiridos durante a socialização familiar. Na matéria, publicada em maio de 1997, intitulada "Diário de um Orgasmo", escreve-se: "A capacidade de chegar ao orgasmo está na cabeça não no corpo". A preparação da "cabeça" inclui a liberação de valores transmitidos pelos pais, tornando-se uma mulher "aberta", "quente" pronta para experimentações sexuais. Esta é a amante ideal: "A amante das fantasias masculinas não tem seios empinados, a cinturinha de vespa ou a barriga mais reta do mundo. Mas é uma mulher que respira sexualidade e adora aprender cada vez mais todas as maneiras de dar - e receber - prazer. Vem, a gente vai ensinar o truque para você" (05/1997).

A revista Nova conclama: Você pode conseguir o orgasmo! Você é livre para tal! Então, por que justamente eu não consigo? Perguntamse as mulheres deste cenário disciplinador. Em matéria da edição de março de 1998, uma entrevistada se queixa: "Me sinto culpada quando não fico excitada". Nesse ideário, qualquer problema é remetido à esfera individual - falta de conhecimentos ou bloqueios emocionais advindos de uma educação repressiva.

Porém, se às mulheres é conferido o poder de realizar suas escolhas sendo vistas como autônomas, especialistas convidados pela revista oferecem uma série de conselhos e critérios para realizá-las, o 
que, implicitamente, conduz ao reconhecimento de uma incapacidade do sujeito em definir e fazer suas próprias escolhas. Além disso, garantir um bom desempenho sexual implica uma atualização constante das técnicas (posições, gestos, falas etc.). Instala-se uma corrida na qual a mulher sempre está desatualizada em relação a algo "novo". Nesse sentido, na Nova de setembro de 1997 escreve-se: "Se pensa que já leu tudo o que existe sobre o prazer, este novo método vai fazer você mudar de opinião". Assim, a cada número a revista propõe uma "solução mágica" que pode resolver questões axiais, mas no número seguinte há sempre uma nova - melhor, mais simples, mais rápida que a primeira. Com a sua máquina de soluções, a revista legitima sua utilidade movida por esse mecanismo, e o consumidor nunca está satisfeito porque jamais sabe o suficiente.

Ensinam-se estratégias para aumentar o prazer do homem, fazendo que ele obtenha o máximo de satisfação. Na edição de fevereiro de 1998, por exemplo, expõe-se como chamada de capa: "Posições Sexuais. Qual eles mais gostam; as táticas que usam para conseguir o que querem. 4 homens confessam!'. Se à mulher do século XIX foi atribuída a responsabilidade pela harmonia do lar e da família (GALINDO, 1999), à mulher do final do século, atribui-se como responsabilidade principal o êxito da vida sexual.

\section{Do amor romântico e seus deslocamentos}

Ao passo que nas capas o sexo é o grande protagonista, nas matérias, o amor é definido como a única forma possível de alcançar felicidade plena. Tendo como matriz básica de ancoragem o modelo romântico, o sentimento amoroso é definido como superior, em intensidade e qualidade, a qualquer outra experiência. A experiência sexual nem sempre traz felicidade, o amor, por sua vez, caso traga sofrimento não se tratava de um verdadeiro amor. Itens como fidelidade, eternidade, planejamento futuro estão presentes. Porém, diferentemente da posição de passividade, na qual a mulher se encontrava no jogo amoroso, tal qual idealizado no projeto romântico, admite-se abordar um parceiro com uma investida direta. 
Em matéria publicada na edição de janeiro de 1997, aconselha uma terapeuta: "Sem um investimento emocional, é muito comum a gente achar que está faltando alguma coisa". O sexo pleno seria aquele no qual a intimidade é uma premissa: "No final das contas, o sexo que interessa - sexo quente, cheio de fantasias, sexo carinhoso, mas sempre sexo honesto, aberto, íntimo - é o sexo que se faz quando se está verdadeiramente ligado à vida do seu bem amado, na cama e fora dela" (01/97).

O aumento da duração da relação é visto como um objetivo a ser alcançado, mas constantemente procura-se minimizar as culpas pelas tentativas fracassadas. A fidelidade também não significa sempre exclusividade sexual. Mesmo minoritariamente, admite-se a possibilidade de realizar experimentações sexuais com outros parceiros desde que não haja investimento emocional. Assim, o ideário romântico é conciliado com a cultura de consumo que circula na revista, na qual se procura minimizar o máximo possível qualquer possibilidade de sofrimento, oferecendo-se soluções estratégicas. Tal como aponta Costa (2005), o consumo de rituais amorosos constitui um dos núcleos do amor romântico contemporâneo.

O sexo sem vínculo afetivo é admitido, porém ressalva-se que é preciso ter claros os objetivos dessa relação, controlando a tendência feminina de "confundir" sexo com o amor - intimidade sexual com intimidade amorosa. Acredita-se na existência de uma satisfação sexual independente da satisfação amorosa, mas esta possui status inferior à experiência de conjugação entre sexo e amor. Situação na qual o contato sexual atinge o máximo de satisfação. Essa configuração é bem diferente da encontrada por Denise Alves (1985) na Nova publicada até 1984, em que as relações sexuais sem plano de uma relação duradoura eram admitidas condicionadas à saída da mulher do seu círculo de convivência habitual: numa excursão, numa viagem de férias. Jamais sendo admitidas relações sexuais com um "amigo colorido", por exemplo.

O amor é significado como algo imanente ao feminino. Naturalmente, a mulher tende a ser fiel, a procurar um homem e a desejar que a parceria seja duradoura. Em uma matéria chega-se a perguntar por que as mulheres agora independentes, liberadas "ainda" 
precisam de um homem para "chamar de seu". Há décadas atrás, falar em amor significaria, automaticamente, pensar no desejo de fundar uma família, concretizado no momento em que nasceriam os filhos. Mas os tempos mudaram e na Nova, o amor tem como espaço de atualização uma relação afetiva vista como fim em si mesma.

Nos relacionamentos amorosos, as dificuldades mais citadas são: (1) saber se o homem efetivamente deseja compromisso ou seus interesses centram-se na satisfação sexual unicamente; (2) encontrar o homem certo; (3) estabelecer diálogo; (4) saber até que ponto ceder para agradar o parceiro; (5) esperar ou tomar a iniciativa; e (6) evitar que a atração física recrudesça com o tempo. Frequentemente tais dificuldades são expostas conjuntamente com propostas de soluções que podem ser dadas por homens, especialistas ou por casais experientes, tal qual ilustrado na matéria: "Querida, precisamos conversar", publicada na edição de junho de 1998. Nela, ensina-se como fazer para que o parceiro tome a iniciativa de conversar sobre a relação.

$\mathrm{O}$ amor almejado é duradouro, baseado em projetos de vida em comum, mas se vê sempre ameaçado pela diminuição da atração sexual que é um dos seus pilares, sendo o consumo uma das alternativas centrais para a resolução da referida tensão. O amor romântico está incorporado a um conjunto de objetos, locais, rituais que o aproximam de um mercado e da economia (COSTA, 2005). Admite-se como natural que, com o tempo e a rotina, a atração física diminua, de modo que é preciso sempre inovar sexualmente. Em matéria dedicada a discutir como manter o casamento, aconselha-se: "Um filme erótico, um cenário para o encontro de amantes, um bom vinho e um aperitivo especial para apimentar o programa. Ah, não esqueça de usar uma lingerie nova!" (07/98).

Ao mesmo tempo em que ao amor é atribuído o papel principal no projeto de felicidade, pressuposto básico do romantismo, passa por um processo de desmistificação. $\mathrm{O}$ amor sacralizado associado a um sentimento etéreo, fruto de uma comunicação entre 'almas', cede espaço para um amor assimilado à ação concreta dos indivíduos - a um jogo de posturas, comportamentos, encontros marcados. Em uma matéria comparam-se os primeiros passos para estabelecimento do vínculo às habilidades exigidas durante uma entrevista de seleção profissional: "Achamos que o amor é cego, um sentimento irracional. 
Só que nesse começo, não. É como uma entrevista para conseguir uma colocação" (03/98).

A separação ou dissolução converte-se em uma premissa do casamento ou do morar junto: casa-se com a possibilidade de separação. Mas não se questiona o arranjo amoroso em si, as separações são vistas como um momento de reflexão, uma pausa entre a tentativa malfadada e a subsequente. $\mathrm{O}$ casamento não perdeu seu status de apogeu de uma relação afetiva, mas é redefinido em função do questionamento da eternidade, associada ao enlace amoroso. Uma matéria referindo-se a um homem nervoso com a idéia de dividir o apartamento aconselha a dizer que morar junto não é irreversível: "Embora morar junto seja um compromisso sério, não é irreversível. [...] Se não gostar pode ir embora!"(02/98). Apesar da referência ao "morar junto" como um arranjo legítimo, o casamento com pedido formal e aliança - molde tradicional - ainda é envolvido de certo glamour em duas matérias dedicadas ao dia do "sim".

No que se refere ao quesito fidelidade, em algumas matérias diz-se que esta inclui a dimensão sexual e afetiva. Uma ilustração pode ser encontrada na matéria "20 maneiras de manter o seu relacionamento à prova de traição". Apoiando-se em estatísticas norteamericanas, afirma-se que "a probabilidade de sua cara metade dar uma escorregadela é grande, o jeito é garantir a saúde da relação para que as tentações passem longe do seu casamento". Entre as vinte sugestões dadas está a seguinte: "deixar bem claro que, para você, a fidelidade é fundamental para a saúde!”. Em outras matérias, que focam as experimentações sexuais, a fidelidade é definida pelo investimento afetivo e não, necessariamente, pela exclusividade sexual. Tal configuração é caracterizada por Mello (1997) como uma moral dual, definida como aquela que distingue entre prazer sensual e amor, sendo a fidelidade definida em função do compromisso afetivo.

As mulheres querem compromisso, homens o temem - essa é uma equação recorrente na Nova. Diante do "medo de compromisso" atribuído ao homem, a revista oferece uma série de indicadores para identificar as intenções e aspirações masculinas. Numa matéria assinada por um homem, este se propõe a tratar sobre "por que as mulheres querem tanto que a gente diga "eu te amo"”. Arremata ele: 
"Seja como for, no começo da relação, a maioria das mulheres se satisfaz com isso (eu adoro você etc.) mas, passado algum tempo, não aceitam mais substitutos. Desconfiam que esse gostar de que você fala é exatamente o que elas querem" (01/98). Em uma outra matéria afirma-se que "no fundo" os homens "estão loucos para se casar". É só uma questão de saber o momento certo para falar em "compromisso" ou "ter paciência" para esperar ele se decidir. Através da alusão a alguns dados de pesquisa, a revista mostra que no "fundo", "os homens estão em busca das mesmas coisas que nós. Querem viver felizes com uma pessoa carinhosa e interessante. [...] nem acham que a paixão e o amor bastam para fazer o sucesso do casamento." (NOVA, 12/97).

Casais felizes e bem sucedidos são mencionados pela Nova como exemplos da possibilidade de obtenção da satisfação amorosa falam sobre suas experiências, mostram a viabilidade de ser feliz no amor. Se no sexo há restrições a determinadas práticas, no sentido de que podem causar sentimentos de insatisfação, queda na auto-estima, ao amor não é feita qualquer restrição. Quanto mais amor, melhor, exceto quando em decorrência dele sofre-se, mas aí não era verdadeiramente amor.

\section{Considerações finais}

Nos números analisados da Nova Cosmopolitan, o sexo se inscreve na busca pela intensificação das sensações, avizinhando-se do consumo de exercícios que faz da academia espaço central na contemporaneidade. No sexo, nada pode ser banal, nem impossível. O ideal sexual, que tem no orgasmo sua imagem prototípica, configurase um percurso árduo, difícil e competitivo que conduz a matérias dedicadas a técnicas de aumento do prazer e também a angústias, dúvidas e ansiedades. Cria-se o cenário para uma diversidade de infernos pessoais, uma vez que ter uma boa vida sexual é uma questão de habilidade pessoal.

Os corpos moduláveis e excitáveis se inscrevem numa ética individualista voltada para o imediato. A exacerbação das sensações substitui o controle e ocultação dos corpos que, historicamente, 
caracterizou a apresentação do sexo na imprensa feminina. $\mathrm{O}$ cultivo das condições físicas resulta, por sua vez, de um investimento em ginástica e treinamentos, de modo que, metaforicamente, o sexo requer o coração aos pulos do exercício físico, instaurando uma pedagogia da sexualidade assentada sobre corpos excitáveis.

No lugar do mediano cotidiano, advém uma verdadeira obsessão pelas sensações que devem ser encontradas nos pontos exatos, nas posições determinadas, nas carícias calculadas. E, ao lado das sensações, as insatisfações calculadas, pois ninguém acredita nas promessas eternas que constituem a razão de ser de boa parte das revistas femininas. São preconizadas práticas que transitam entre o corpo excitável (do orgasmo) e automodulável (da ginástica).

Mas, a despeito da exacerbação do sexo, as fichas do prazer, materializado no orgasmo, são jogadas na roleta do amor e, a todo o momento, espera-se o prêmio - nada menos que a felicidade pelo encontro de uma relação afetiva ideal. $\mathrm{O}$ aparente vale-tudo do sexo está condicionado à busca de uma parceria amorosa que, ancorada no ideário romântico de amor, o reafirma e o destradicionaliza. E, nesse contex to, amor e sexo são incorporados à lógica do consumo, mantida pela insatisfação e exacerbação da busca de sensações.

\section{Nota}

${ }^{1}$ Doutora em Psicologia. Professora do curso de Psicologia e do Mestrado em Estudos da Cultura Contemporânea (ECCO) da Universidade Federal de Mato Grosso.

\section{Referências}

ALVES, D. O desencontro marcado: a velha mulher-nova e o machão moderno. Petrópolis, ed. Vozes, 1985.

BARDIN, L. Análise de conteúdo. Lisboa: Edições 70, 1997.

BASSANEZI, C. Virando as páginas, revendo mulheres. Rio de Janeiro: ed. Civilização Brasileira, 1996. 
CARDOSO, E. Imprensa feminista brasileira pós-1974. Revista Estudos Feministas. vol.12, dez. 2004.

BULTONI, D. Mulher de papel: a representação da mulher na imprensa feminina brasileira. São Paulo: Loyola, 1981.

Imprensa feminina. São Paulo: ed. Mandarim, 1986.

COSTA, J. F. Utopia sexual, utopia amorosa. In. Utopia e mal estar na cultura: perspectivas psicanalíticas. São PauloHucitec, 1997.

Sem fraude, nem favor. Rio de Janeiro: Roxo, 1998.

COSTA, Sérgio. Amores fáceis: romantismo e consumo na modernidade tardia. Novos estud. - CEBRAP. . 70, nov. 2005, p.111-124.

GALINDO, D. Educação feminina no século XIX: o grande plano de formar mães e esposas no Padre Carapuceiro (1832-1842). In: Olhares e Diversidades: os estudos sobre gênero no norte-nordeste, Pará, v. $1,1999$.

GIDDENS, A. Transformações da intimidade. Sexualidade, amor e erotismo nas sociedades modernas. São Paulo: Editora da Unesp, 1993.

KEHL, M. Com que corpo eu vou? In: GOLDENBERG, Miriam. (org.). Nu \& Vestido: Dez antropólogos revelam a cultura do corpo carioca. Rio de Janeiro: Record, 2002.

MALUF, M. e MOTT, M. Recônditos do mundo feminino. In: História da vida privada no Brasil, vol. 3. São Paulo: Companhia das Letras, 1998.

MELLO, S. Românticos ou narcísicos: um estudo sobre o descompromisso afetivo contemporâneo. ( Dissertação de Mestrado) Universidade Federal do Rio de Janeiro. Rio de Janeiro, 1997. 
MIRA, M. C. O masculino e o feminino nas narrativas da cultura de massas ou o deslocamento do olhar. Cad. Pagu, n.. 21, p. 13-38, 2003.

MORAES, M. Família, feminismo: reflexões sobre papéis femininos na imprensa para mulheres. São Paulo: Edusp, 1981.

NICOLACI-DA-COSTA, A. Mal-estar na família: descontinuidade e conflitos entre sistemas simbólicos. In: Cultura da psicanálise. São Paulo: Brasiliense, 1985.

NOBREGA, S. et al. Do amor e da dor: representações sociais sobre o amor e o sofrimento psíquico. Estudos de Psicologia. (Campinas), v. 22, n. 1. Campinas, 2005.

SOARES, G. Refúgio no mundo do coração: um estudo sobre amor na obra de Rousseau. (Dissertação). Universidade Federal do Rio de Janeiro. Rio de Janeiro, 1997.

LOURO, G. L. (Org.). O corpo educado: pedagogias da sexualidade. Belo Horizonte: Autêntica, 2001.

SAFATLE, V. P. Um corpo obsoleto: sobre a relação entre fragilização das identificações e reconfiguração contínua do corpo. In: COLÓQUIO Internacional "Teoria crítica e educação". Piracicaba : Unimep, 2004. v. 1.

XAVIER FILHA, C. Imprensa feminina - entre modas, bordados, cuidados com a prole e o casamento: dispositivos pedagógicos de revistas femininas. Anais do $16^{\circ}$ Congresso de Leitura do Brasil. Unicamp, 2007. Disponível em: http://www.alb.com.br/anais16/ sem03pdf/sm03ss14_01.pdf. Último acesso: 20/04/2008.

ZUCCO, L.P. e MINAYO, M.C.S. Sexualidade feminina em revista(s). Interface - Comunic., Saúde, Educ., 2008. 


\title{
Pedagogies of excitable and scalable bodies: sex, love and dissatisfactions in the twenty-five years of magazine Nova Cosmopolitan
}

\begin{abstract}
This article discusses the approach of love and sexual themes in women's magazine Nova Cosmopolitan. We analyzed twenty-four issues published between 1997 and 1998, a period that coincides with the commemoration of 25 years of the journal in Brazil. In the journal in question, the sex comes in the search for the intensification of sensations. The exacerbation of sensations and replaces the control of the bodies that, historically, characterized the presentation of sex in women's press. This configuration is incorporated into the logic of consumer dissatisfaction and maintained by the search for sensations exacerbated - pedagogies of excitable bodies of orgasm and the scalable bodies of gymnastics.
\end{abstract}

Keywords: sexuality's pedagogies, love, sex and woman's press.

Recebido em: 14/02/2009

Aceito em: Junho/2009 